\title{
Aleksander (Olek) Pelczynski
}

\section{2-2012}

\section{Edited by Joe Diestel}

Aleksander Pelczynski was a leader in functional analysis for more than half of a century.

Olek (as he was known to most who knew him) worked in Banach space theory much of his later life but previously made serious contributions to infinite dimensional topology and the theory of nuclear Frechet spaces. He kept in touch with workers in all these vineyards and was frequently an inspiration to young workers with keen insights and suggestions. He was famous for his signature question, "What did you prove last night?"

Olek wrote many papers now considered to be classics. In the seventies he concentrated on how Banach space theory interfaced with harmonic analysis, complex variables, and probability. He frequently expressed the opinion that Banach space theory was an area that needed to "test its wares in other areas of mathematical endeavor" and, as was usually the case, he was a leader in such efforts.

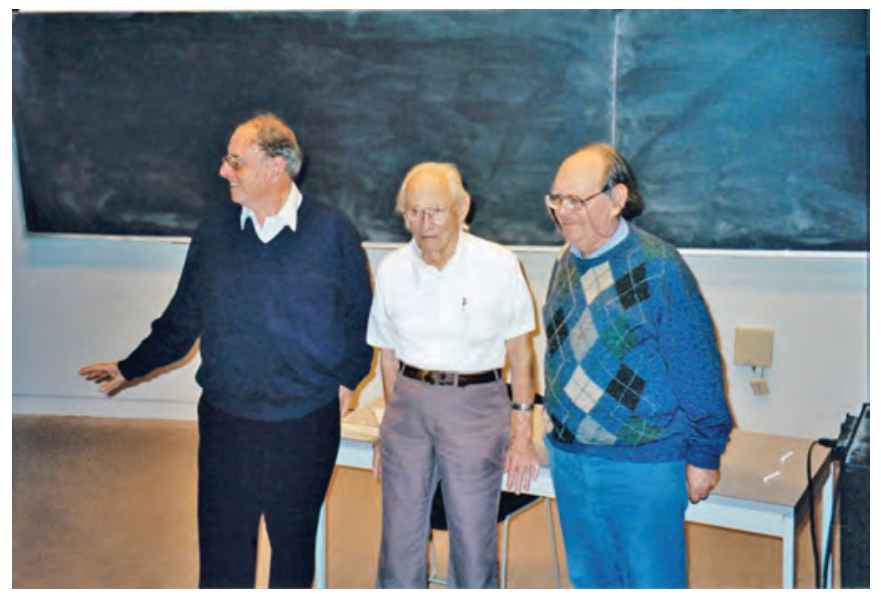

Joram Lindenstrauss, R. C. James, and Aleksander "Olek" Pelczynski.

Joe Diestel is emeritus professor of mathematics at Kent State University. His e-mail address is vectormeasurejoe@gmai 1 . com.

I had the help of many in organizing this ode to Olek, including Nicole Tomczak, Hermann Konig, Stan Kwapien, Tadek Figiel, Czeslaw Bessaga, Darci Kracht, and Angie Spalsbury.

For permission to reprint this article, please contact:

reprint-permission@ams .org.

DOI: http://dx.doi.org/10.1090/noti1464
For many years Olek was the main line of communications between functional analysts from the East and West. Many will remember a one-page statement and proof of Victor Lomonosov's startling theorem on invariant subspaces. This page was the result of Olek's dictating the result to Czeslaw Bessaga, who was in the United States at the time, and requesting that Czeslaw make copies and send them to "our friends in America."

STAN KWAPIEN tells of Olek's early academic life:

In 1950 Olek, along with Czeslaw Bessaga and Stefan Rolewicz, participated in the Mathematical Olympiad for high school students, which was organized in Poland for the first time. Later at the University of Warsaw they met an exceptional team of teachers, including Banach's closest collaborator, Stanislaw Mazur, whose seminar had a decisive impact on their future mathematics. As a $\mathrm{PhD}$ student (1957-58) Olek published fourteen papers, six jointly with Bessaga and one jointly with Bessaga and Rolewicz. One of these papers with Bessaga, "On bases and unconditional convergence in Banach spaces," is one of the most cited papers in functional analysis and is considered by many to be a classic in the area. Olek defended his dissertation in December 1958 after a trip with Orlicz to China, a reward for his achievements in mathematics. For Olek this trip was unforgettable, a trip "to the end of the earth." It is quite likely that the visit contributed to the decision of the Chinese government to implement functional analysis in the basic Chinese curriculum.

\section{BORIS MITYAGIN remembers Olek's time in the Soviet} Union:

In November of 1959, Pelczynski came to Moscow State University for a half year as a visiting researcher. At the time he was interested in problems on nuclear spaces initiated by Kolmogorov and Gelfand. In 1955 Kolmogorov introduced invariants for Frechet spaces based on the growth of compact sets (entropy) in a space. Pelczynski suggested closely related invariants, later called approximative and diametral dimension. These helped explain why various spaces of differentiable functions were mutually isomorphic or not.

I recall fondly when our families spent the summer of 1975 together in Peredelkino near Moscow. Olek's daughter, Kasis, 5, spoke Russian with her mother Svetlana and that summer perfected her skill with the Russian language. 
(Today Katarzyna Pelczynski-Nalecz is Polish ambassador to Russia.) At that time Olek and I succeeded in showing that the Banach spaces of functions analytic in the $m$-disc and continuous on the boundary were nonisomorphic for different $m$. This was a step in a long series of results due to Henkin, Kisliakov, and Bourgain on the isomorphic classification of Banach spaces of analytic or differentiable functions.

VITALI MiLmAN recalls an encounter with Olek while in the Soviet Union:

Around 1968 I was living near Moscow and came to the university to meet Olek. During our conversation Olek said to me, "We are very concerned with the proof of Dvoretzky's theorem and think there is a gap in its proof." The "we" being Joram Lindenstrauss and Olek. Since I was very interested in applications of Dvorezky's theorem, the gap meant many of my results were conditional. However, I thought I knew how to give a full and correct proof and said so to Olek, to which he replied, "Then do it." Olek's push inspired me to write down my proof, something that as a young mathematician I was somewhat intimidated to do-write down the proof of a known result.

\section{Albrecht Pietsch:}

Our most important joint
1969 was a wonderful year for the theory of Banach space geometry interest was operator ideals. At the Moscow IMU Congress 1966, Mityagin and Pelczynski delivered a half-hour report on "Nuclear operators and approximative dimension," in which the concept of a $(p, q)$-absolutely summing operator was introduced. Many years later, it was my great honor for me to act as chairman for Olek's famous onehour plenary lecture, "Structural theory of Banach spaces and interplay with analysis and probability," at the 1983 Warsaw IMU Congress.

\section{J. H. "BEN" GARLING:}

1969 was a wonderful year for the theory of Banach space geometry. In the previous year, Joram Lindenstrauss and Olek Pelczynski had published their seminal paper, which elucidated and built upon Grothendieck's work of the 1950s. In the summer of 1969, a meeting in Warsaw brought together these results and the ideas of Laurent Schwartz and his school concerning measures on Banach spaces and Radonifying operators. The outcome was explosive and the reverberations continue to this day.

\section{BILL JOHNSON:}

The two architects of modern Banach space theory, Joram Lindenstrauss and Olek Pelczynski, both left us in 2012. I met Olek first, in 1971 when he spoke at Tulane University. After a brief exchange of pleasantries, Olek asked me, "What have you proved?" I learned later that this was his standard greeting. I hated it when we were

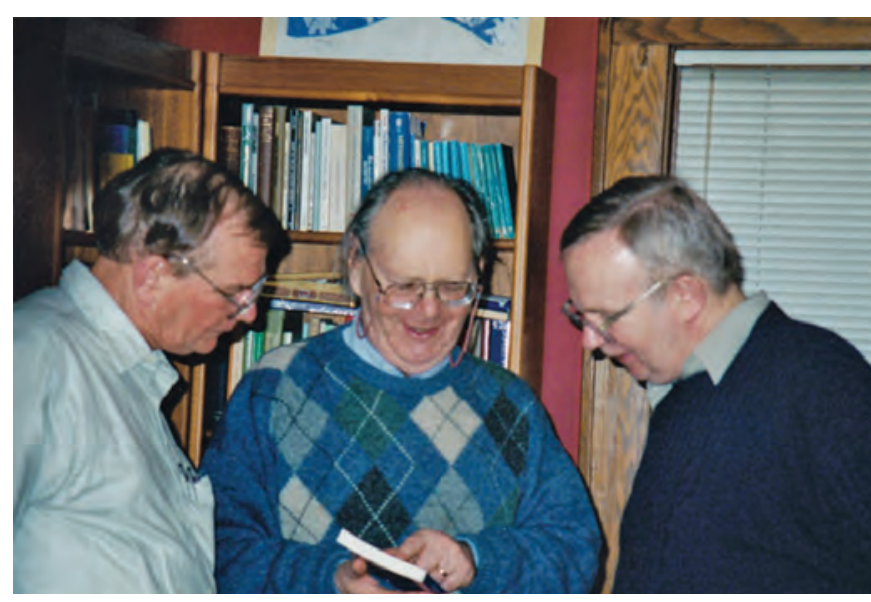

W. B. Bill Johnson, Pelczynski, and Tadek Figiel.

together for some time and I had to answer "nothing" each morning.

My first paper with Olek, which was written jointly with W. Davis and T. Figiel, contained a result that is now in textbooks, namely, that a weakly compact bounded linear operator factors through a reflexive Banach space. Olek was not content with just this basic theorem and pushed to use the interpolation technique we employed to prove other results. This taught me a lesson about being professional: before turning to a different topic, one should work out the ramifications of the arguments and ideas. I was pleased to learn from Google Scholar that this factorization publication is Olek's third most cited paper after his "Absolutely summing operators in $L_{p}$-spaces and their applications" paper with Joram and his "On bases and unconditional convergence of series in Banach space" article with Bessaga. I especially appreciate his series of papers with various people on the isomorphic structure of the Banach spaces $C(K)$. Recently I had occasion to go back to several of these and once again marveled at what he and his collaborators proved at a time when the isomorphic theory had few tools.

The year Olek spent at Ohio State in the 1970s was exciting for the analysts in Ohio. Much of his time was spent preparing for his CBMS lectures in Kent in July 1976.

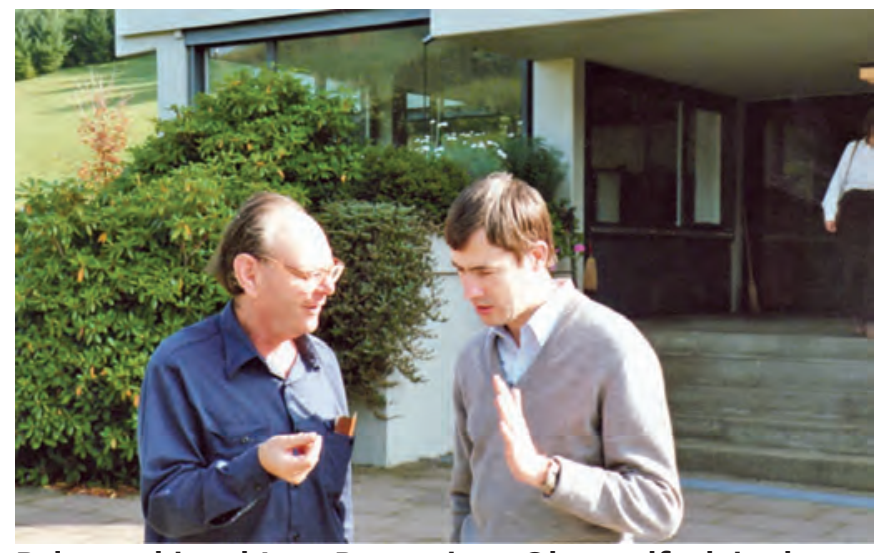

Pelczynski and Jean Bourgain at Oberwolfach in the summer of 1986. 


\section{Olek's book}

...represents

what was at

the time an

amazingly
original
and seminal
collection of
insights

The manuscript he produced for the CBMS regional conference series, "Banach spaces of analytic functions and absolutely summing operators," helped bridge what was then a wide gap between classical and functional analysis. From then until the very end, Olek devoted his time investigating spaces of interest to classical analysts, such as Sobolev spaces and spaces of functions of bounded variation.

\section{JEAN BOURGAIN:}

In 1979, as a member of my habilitation committee at the Free University of Brussels, Olek praised my work but made it clear that a few in the field had produced superior theses and that in his view it was time for me to work on something else. So I borrowed his Banach Spaces of Analytic Functions and Absolutely Summing Operators from my advisor and asked which of the many problems had been solved and which were still open. Fortunately, there were plenty of unsolved questions left, and they became my research focus for the early eighties. More importantly, they naturally led to my in-depth study of various topics in classical analysis. Olek's book lies indeed at the interface of classical function theory and functional analysis and represents what was at the time an amazingly original and seminal collection of insights. Some problems got solved; some remain open until today. Most notorious perhaps is the issue of whether or not the space of bounded analytic functions on the disc has the approximation property. In his book Olek did not express himself one way or the other, but he did so privately (and our views differed).

Discussions with Olek were invariably entertaining because of his highly personal views on many issues in and outside math and his direct way of expressing his frank opinions. I recall him making the comment on more than one occasion, "If you want a real achievement, you should not have a survivor's mentality" (though it was never quite clear to me what the second part of the sentence means for a mathematician).

\section{HERMANN KONIG:}

In 1968, Olek published (jointly with Joram Lindenstrauss, who sadly also died in 2012) one of the most important papers in Banach space theory, "Absolutely summing operators in $L_{p}$-spaces and their applications." This paper reformulated Grothendieck's results in "Resume de la theorie metrique des produits tensoriels topologiques" in tensor product-free language and solved various open problems in Banach spaces. It launched the local theory of Banach spaces based on uniform estimates of finite-dimensional invariants, rejuvenated the area of Banach spaces, and resulted in an outburst of activity in Banach spaces and operator theory.
Olek had an encyclopedic knowledge of functional analysis and related areas and a keen interest in new results. "What did you prove recently?" was one of his typical comments. He had an incredible memory to reproduce proofs he had once read or heard about.

Before the fall of the iron curtain Olek was one of the few mathematicians who were able to travel rather freely from Poland to the West and throughout the East. He was in a unique position to communicate new ideas between the East and the West.

Olek had a dry sense of humor, which showed at times when he expressed everyday events in mathematical terms. Once coming from Warsaw by train to Kiel he had to pay 25 Marks for the ticket from the East-West German border and 24 Marks for the return trip. He concluded that "the German railway system is noncommutative."

\section{NiCOLE TOMCZAK-JAEGERMANN:}

I met Professor Pelczynski in the mid-sixties when I was a second year student at Warsaw

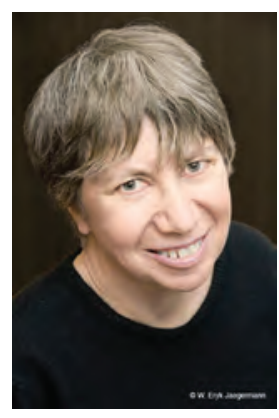

Nicole TomczakJaegermann University. At that time I was trying to find mathematics that I liked. I visited Pelczynski's functional analysis lectures a few times and then stayed. When the time for exams came in the spring, my third year colleagues suggested I ask for an exam and get credit for the course a year in advance. Pelczynski agreed and we walked together to the Palace of Culture. I remember that this approximately two kilometer walk took about an hour and on the way I had to answer a pile of apparently casual questions covering almost all the material of the course. This turned out to be just the beginning: after arriving at his office in the Palace, Pelczynski informed me, "Now the exam starts!" I passed.

While I was working on my doctorate I was invited to Poznan to give a lecture. After the lecture there were some questions and at the end, Professor Musielak, who was my host, remarked that it was very obvious whose student I was: all the problems I was working on were either open or trivial.

\section{TOMEK SZANKOWSKI:}

When I started my undergraduate studies in 1963 the mathematics in Warsaw was still dominated by the celebrities of the pre-war Polish school centered on point set topology and set theory. Pelczynski was then an "angry young man," vigorously trying to modernize the teaching and research of analysis in Warsaw. For example, he created quite a panic when he decided to teach advanced calculus the Bourbaki way; this was the most memorable course of my undergraduate study. On the research level, Olek was then pursuing two big projects: infinite dimensional topology (working closely with Bessaga) and operator ideals (as a tool for Banach space theory). In both areas he made major contributions. His book with Bessaga, Selected Topics in Infinite-Dimensional Topology, is the ultimate text on the subject, while his paper with Joram 


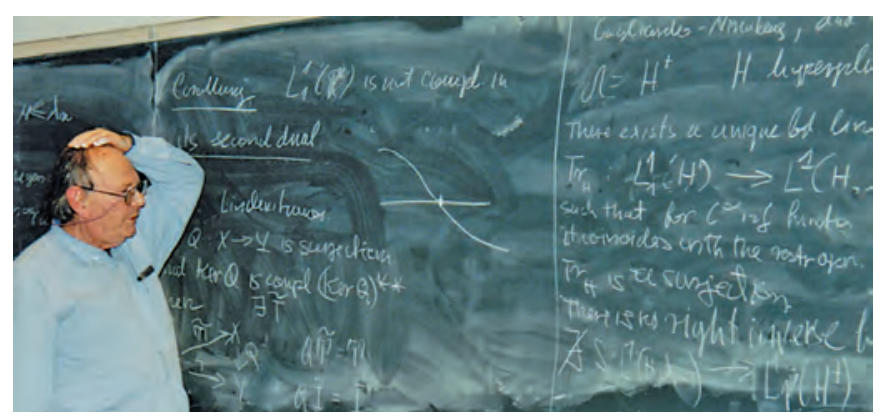

Pelczynski lecturing at Kent State.

Lindenstrauss has been a most influential contribution to Banach space theory.

I got to know Olek personally through an undergraduate seminar on "Extensions and Averagings." I managed to solve an open problem he posed in the seminar and was very conceited about it. Olek brought me back to reality with the wry remark, "Still, you are no Grothendieck." But, of course, it was only his style; as an advisor he was extremely supportive, stimulating, and also demanding. Regularly my telephone woke me up at 8 am: "What have you proved today?" was the standard question.

For years to come I kept meeting Olek at various conferences, always being asked, "What have you proved recently?" Recently I asked him a technical question, one that had puzzled me for some time. The next morning he had a solution. Mathematics was always the first and main topic of his conversation. Only when he'd exhausted the discussion on this would he change the topic, usually to history, his great hobby. I will miss these lively and entertaining conversations.

\section{NIELS NIELSEN:}

I met Olek for the first time in 1968 when he visited Aarhus University in Denmark. I discussed a lot of mathematics with him and was struck by how easy it was to communicate with him and how much care he took of a young person. This had an enormous impact on the rest of my mathematical life.

To many people Olek could seem a bit impractical, but when it came to important things he was very efficient. If a bureaucrat told him something was impossible he would take the mathematical attitude and with his dry humor claim, "Your statement requires proof!" After some discussion most bureaucrats would give up.

I visited him in Warsaw in the late 1980s. Olek greeted me with, "Welcome to free Poland!" and together we celebrated the downfall of the communist regime in Poland, a thing not expected in our lifetime.

\section{CARSTEN SCHUTT:}

Olek was one of the reasons I chose Banach space theory as my field of research. His Studia Mathematica paper with Joram Lindenstrauss on "Absolutely summing operators in $L_{p}$-spaces and their applications" explained much of Grothendieck's work in functional analysis and started the local theory of Banach spaces. Olek once told me that if it had been submitted somewhat later it might not have been accepted because of the political situation in the Middle East.

When meeting a colleague Olek would ask, "What is new in mathematics?" If a student or junior person would answer "nothing," he had a particular way of saying "I see" which instantly made you feel bad.

On Saturday evening December 12, 1981 I boarded an overnight train in Vienna heading for Warsaw. The next morning turned out to be beautiful with sun shining and snow on the ground. As promised, Olek was at the train station to pick me up. His first words were, "We have martial law." It took me some time to realize what it meant. While still at the train station Olek showed me one of many posters people could read telling them what was allowed and what was forbidden. He did not lose his sense of humor, translating a poster pointing to the edict "No public performances" and saying, "This applies to you." At the time I occasionally performed magic.

I stayed at his place. He summarized the situation saying, "Probably you have to stay longer which is good, so we can do mathematics." But it was clear that Olek was worried. He would quietly fill the bathtub with water in case the water supply would end. Meetings and gatherings were not allowed, but seminars were, and a Russian colleague and I were giving seminar talks. After the talks Olek apologized, "I am sorry but people were not really listening."

\section{JOE DIESTEL:}

Olek was a very generous man. In 1976, Jerry Uhl and I were putting the finishing touches on a book and Olek visited Kent to give a colloquium talk. During his talk he gave a proof that the disc algebra, which was known to have a Schauder basis, did not have an unconditional basis; more precisely, the disc algebra did not have local unconditional structure (LUST, as Olek referred to the property to make it more "interesting") and so was not even isomorphic to a Banach lattice. His proof used many of the best results we were presenting in our book. He told us he'd fashioned the proof just for us and agreed we could use it in our text, if we so desired. We did and it added much to our Notes and Remarks.

\section{STANISLAW SZAREK:}

As a student at Warsaw University I took a seminar-type class co-taught by Olek and Staszek Kwapien on sequences and series in normed spaces. At the first meeting we were given a list of topics to present and problems to solve. Most of the problems were just hard exercises, but some were true open problems. There was a lot of enthusiasm, both on the side of the instructors and on the side of the participants. I guess it was that seminar that attracted me to functional analysis; before that, I was primarily interested in mathematics that was directly relevant to physics. One of the open problems led the following year to my first paper on the best constants in the Khinchine inequality. It was some time around then that Olek became my official advisor. We met frequently on a one-to-one basis and all those encounters were invaluable to my development as a mathematician. On the one hand he was incredibly generous with his time, knowledge, and ideas. 


\section{GHzürich}

\section{Professor of} Mathematics

$\rightarrow$ The Department of Mathematics www.math.ethz.ch at ETH Zurich invites applications for the above-mentioned position.

$\rightarrow$ Successful candidates have an outstanding research record and a proven ability to direct research work of high quality. The new professor will be expected, together with other members of the Department, to teach undergraduate level courses (German or English) and graduate level courses (English) for students of mathematics, natural sciences and engineering. Willingness to participate in collaborative work both within and outside the school is expected.

\section{$\rightarrow$ Please apply online at}

www.facultyaffairs.ethz.ch

\section{$\rightarrow$ Applications include a curriculum} vitae, a list of publications, a statement of future research and teaching interests, and a description of the three most important achievements. The letter of application should be addressed to the President of ETH Zurich, Prof. Dr. Lino Guzzella. The closing date for applications is 28 February 2017. ETH Zurich is an equal opportunity and family friendly employer and is further responsive to the needs of dual career couples. We specifically encourage women to apply.

\section{COMMUNICATION}

On the other hand, he was tough, his legendary inquiries "What did you prove this week?" being just one example. With time, I got to know him as a human being and I think I could-with pride-call myself his friend.

We close with CZESLAw BESSAGA's eulogy to Olek:

Olek, what would you like to hear? What would you want me to tell here? Most likely it can’t be of your enormous scientific achievements nor of the respect that you enjoyed in mathematical circles worldwide. You assessed the value of your results soberly with no false modesty. What interested you most were results of other mathematicians, especially colleagues and pupils. Often you started conversations with the question: "What did you prove lately?" So you would surely be pleased if we, one after another, tell about our latest achievements. There will be a more suitable time for that.

Outside of mathematics you were interested in history and literature. Perhaps not many of us who are gathered here know that you were the initiator and creator of the unprinted journal Acta Graphomanica Mathematica [with its] prose and poetry, lots of humor and satire. ... I remember political satire-a famous series of zlomeks authored by many mathematicians that promoted the action of collecting scrap metal. I also remember epitaphs of mathematicians living in Warsaw at the time. Finally, Olek, I remember your elegant limericks, sonnets, and fraszkas, somewhat in the spirit of Julian Tuwim.

Olek, I wish that, thanks to your papers and your disciples, you inspire many future generations of mathematicians helping in the development of Polish mathematics, especially of Banach spaces.

Editor's note: Notices regrets the delay in the publication of this article.

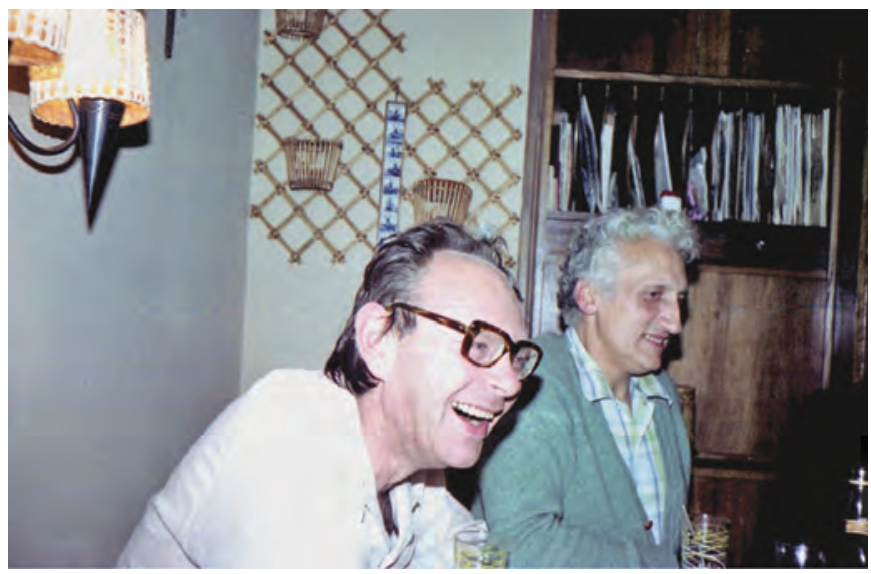

Pelczynski and Czeslaw Bessaga.

\section{Photo Credits}

Photo of Nicole Tomczak-Jaegermann is courtesy of W. Eryk Jaegermann.

All other article photos are courtesy of Joe Diestel. 